\title{
Os Investimentos Franceses no Brasil: o caso da Brazil Railway Company (1900-1930)
}

Flávio $A . M$ de Saes

Departamento de Economia FEA/USP

Os investimentos franceses no Brasil, entre 1900 e 1930, já foram objeto de alguns estudos (1), que definiram as linhas gerais e os momentos críticos desse movimento de capitais.

Neste artigo, pretendemos investigar um caso de aplicação de capitais franceses no Brasil. Trata-se do investimento realizado na Brazil Railway Company, empresa registrada nos Estados Unidos mas cujos recursos foram levantados nos mercados de capitais da Europa. Apesar de se tratar de uma empresa norte-americana, acreditamos que seja possível teconhecer nela a maior concentração de investimentos franceses no Brasil entre 1900 e 1930. Justifica-se, desse modo, seu estudo específico por quem se interessa pelo conjunto dos investimentos franceses no Brasil.

Evidentemente, o estudo do caso da Brazil Railway Company não basta para generalizações a respeito dos capitais franceses investidos no Brasil. Ainda assim, acreditamos que ele possa revelar aspectos importantes que sirvam como hipóteses para futuras e mais profundas pesquisas.

I. A Brazil Railway Company, a situação da economia brasileira e os investimentos franceses no Brasil no começo do Século XX.

A Brazil Railway Company foi formada em 1906, de acordo com a legislação do Estado do Maine (EUA), com o objetivo de controlar o sis-

(1) - MAURO, Frédéric. Las Inversiones Francesas en Brasil. Siglos XIX y XX. In: Capitales, Empresarios y Obreros en America Latina. Stockholm, 1983,. t. II, além de traçar um quadro geral apresenta minucioso levantamento bibliográfico a respeito do tema. 
tema ferroviário do sul do Brasil, então de propriedade de diversas empresas brasileiras ou não. O grupo que a organiza já participava (ou participara) de outros empreendimentos no Brasil, tais como a São Paulo e a Rio de Janeiro Tramway, Light and Power Company. O mesmo grupo mantinha outras empresas de serviços de utilidade pública na América do Norte.

A Brazil Railway parece, no entanto, ganhar uma estrutura independente das demais empresas citadas, passando a identificar-se progressivamente com seu principal dirigente: Percival Farquhar. Um fato, no entanto, parece ser comum ao estabelecimento dessas e de outras empresas estrangeiras a partir de 1900: uma conjuntura econômicä particularmente favorável à penetração do capital estrangeiro, fato que pode ter conduzido. ao menos em parte, a uma atitude de aceitação, entre certas classes no Brasil, da entrada desses capitais.

\section{Qual ế essa conjuntura?}

Como sabemos, nos anos finais do Século XiX, o Governo brasileiro encontra-se em posição de insolvência diante de seus cređores estrangeiros. Em 1898, o chamado Funding-Loan - uma espécie de moratória - exigia em contrapartida medidas rigorosas de política econômica. Em particular, a política monetária de caráter restritivo, cujo objetivo era a valorizaçãc da moeda nacional (em termos de divisas), ao mesmo tempo anunciava un período de crise marcado pelo grande número de falência de empresas financeiras, comerciais e industriais. A estes fatos se associa uma tendência ao declínio dos preços internacionais do café a produzir efeitos adversos na balança comercial brasileira, sendo também um dos fatores que conduz à crise. Em 1906, alguns Estados produtores de café formalizam um Convênio para a defesa do produto por meio da compra dos excedentes. O financiamento das compras supunha, no entanto, a obtenção de empréstimos externos. (2)

Desse modo, num momento em que os mercados internacionais de capita1s estão à procura de novas aplicações, encontramos no Brasil uma situação geral de crise econômica que cria amplas facilidades para a penetaçăo do capital estrangeiro.

Não é necessário insistir também sobre o fato de, nesta primeira década do Séculc XX, ter sido particularmente intensa a exportação de capitais franceses, principalmente pela emissão de títulos colocados na Bolsa de Paris. O movimento de capitais franceses para o Brasil faz parte, por-

(2) - Para uma descrição geral e dados quantitativos sobre o período, ver: Vilella, A. e Suzigan, W. Politica do Governo e Crescimento da Economia Brasileira. 1889-1945. Rio de Janeiro, IPEA/INPES, 1973. 
tanto, de processo mais amplo que devemos aqui registrar, mesmo sem podermos estudá-lo com maior cuidado.

Convém támbém, neste passo, fazer uma referência ’̀ magnitude dos capitais 11 anceses investidos na Brazil Railway Company. Mesmo sem se tratar de uma empresa francesa, ela concentra grande parte dos investimentos franceses no Brasil. Apesar da dificuldade de estabelecer dados quantitativos precisos, convém indicar alguns números expressivos, mesmo quando encarados com as necessárias reservas.

Em 1922, a Embaixada francesa no Brasil enviou ao Ministério das Relações Extericres de seu país uma estimativa, para o ano de 1914, do montante de investimentos franceses no Brasil, estiniativa essa apresentada por uma revista brasileira - o Monitor Mercantil (3):

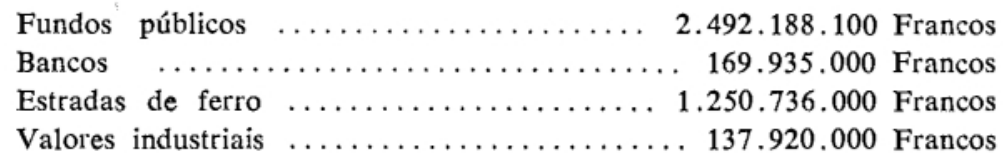

num total aproximado de 4 bilhões de francos

Em 1916, uma nota divulgada pelo "Office National des Valeurs Mobiliers" estimava o montante de capitais franceses investidos na Brazil Railway e associadas em pouco mais de um milhão de francos, especificados a seguir (4):

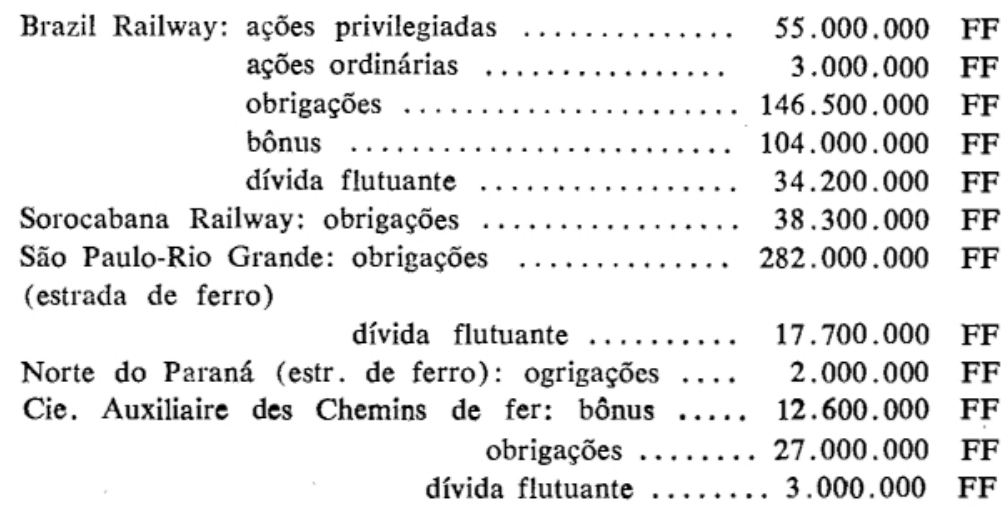

(3) - Ministère des Finances. (Archives). B. 32.767. Ambassade Française au Brésil à Ministère des Affaires Etrangères. 24-11-1922.

(4) - Ministère des Affaires Etrangères. (Archives). Correspondence Politique et Commerciale. Vol. 33, p. 91/100. Note sur l'état de la reorganization de la Brazil Railway Co. $(10-12-1916)$. 
Porto do R. Grande do Sul: ações ........... 5.000.000 FF

obrigações .......... 109.000.000 FF

dívida flutuante ....4 43.800.000 FF

Porto do R. de Janeiro: ações .............. 3.000.000 FF

obrigações ............ 12.500.000 FF

Porto do Pará: obrigações ................ 109.000.000 FF

dívida flutuante $\ldots \ldots \ldots \ldots \ldots \ldots \ldots$ 7.000.000 FF

TOTAL: $\quad 1.014 .600 .000 \quad \mathrm{FF}$

Mesmo que estas indicações sejam precárias e imprecisas (e não devem sê-las de todo), podemos admitir que importante parcela dos capitais franceses aplicados no Brasil o tenham sido na Brazil Railway Company. A acreditar nos dados arrolados, tal parcela aproximar-se-ía de $25 \%$.

Esta breve relação de títulos emitidos pela Brazil Railway e suas associadas já antecipa a amplitude que assume o conjunto de negócios em que se envolve a empresa em seus anos de máxima expansão. Antes de investigarmos esse processo com mais cuidado, cabe uma breve nota sobre a organização da Brazil Railway Company.

\section{A Estrutura da Brazil Railway Company.}

A Brazil Railway tinha as características do que se entende por uma empresa "Holding". Ou seja, por meio de participação acionária, ela controlava amplo conjunto de outras empresas. Há, no entanto, algumas particularidades significativas para a compreensão de sua estrutura e de sua dinâmica, em particular do processo que conduz a empresa a grave crise em 1914 e a sua total reestruturação nos anos posteriores à Primeira Guerra Mundial.

Em primeiro lugar, cabe entender as razões de sua filiação jurídica no Estado do Maine (EUA). Algumas referências anotadas afirmam que tal ocorria pela excessiva liberdade da legislação daquele Esstado norte-americano para o registro de novas sociedades por ações. Em particular, ad. mitia-se a constituição e o registro de uma empresa sem que tivesse ocorrido a integralização em dinheiro de qualquer parcela do capital. Assim, a Brazil Railway (e suas associadas constituídas naquele Estado, como a Sorocabana Railway), embora tivessem um capital autorizado substancial (no caso da Brazil de quarenta milhões de dólares), não recebiam, em sua constituição, aportes de dinheiro expressivos (no caso da Brazil Railway, de apenas 900 dólares) (5).

(5) - A legislação brasileira, à época, exigia o depósito de $10 \%$ do capital nominal em espécie para o registro da sociedade. 
A operação seguinte constituía a primeira fonte de grandes lucros para os fundadores da empresa: obtida a concessão de algum serviço público, a empresa pagava em ações aos indivíduos que haviam obtido a concessão (no caso, seus fundadores), como pagamento por gastos e serviços prestados. Mesmo que tais serviços tivessem um valor, tudo indica que o grupo fundador acabava por absorver a totalidade das ações representativas do capital da empresa sem efetivamente despender uma soma de dinheiro equivalente ao capital.

Pcdemos admitir duas explicações para este fato: por um lado, como por vezes se justificavam os próprios fundadores, tratava-se do pagamento por uma propriedade (no caso, a concessão do serviço público) que tinha um certe valor. Do ponto de vista econômico, sste "valor" seria igual à renda futura esperada dessa concessão, devidamente rapitalizada (ou seja, calculada em termos de seu valor atual). Teoricamente, essa renda capitalizada seria exatamente o preço pago aos fundadores por cederem suas concessões à empresa. Resta saber em que medida o preço pago em ações eta superior ao efetivo valor daquela renda capitalizada.

Outra explicação possível passa pelo conceito de "lucro do fundador": como há uma diferença entre a taxa de lucro corrente e a taxa de juros médja vigente no mercado, é possível remunerar um capital que efetivamente não foi realizado em dinheiro. Em outros termos, se a taxa de lucro é de $6 \%$ e a de juros $4 \%$, para um capital efetivamente realizado de 1.000 , obtemos um lucro de 60 em um ano, embora só seja necessário pagar 40 (ou seja $4 \%$ ) aos "rentistas" proprietários de ações ou obrigações. Os 20 restantes podem ser desviados para remunera" um "capital" não realizado em dinheiro, transformando-se, portanto, num lucro dos fundadores ou dirigentes da empresa.

No caso da Brazil Railway, a questão a colocar é a da relação entre o capital-ações, em geral "distribuído" aos fundadores( quer dizer, não realizado em dinheiro) e o chamado capital-obrigações (efetivamente realizado): em suma, qual é a carga relativa que o capital obrigações deve suportar para remunerar o capital-ações.

É claro, a própria emissão de obrigações era outra fonte de lucros para os fundadores ou para os banqueiros a eles associados. Evidentemente, estes lucros derivados do lançamento de obrigações (tipo da obrigação, comissões) constituiam carga adicional sobre os recursos efetivos à disposiçâo da empresa. Em outros termos, um capital efetivamente 1ealizado em dinheiro devia remunerar um capital nominal muito supericr.

No plano genérico, estes são elementos presentes na estrutura da Brazil Railwy Company e que se refletem nas dificuldades que a empresa enfrenta a partir de 1914 . 
Quanto ao seu caráter de "holding", manifestava-se ele pelo fato de a Brazil Railway não operar diretamente nenhuma empresa concessionária de serviço público, mas simplesmente de possuir ações e obrigações de empresas concessionárias. Tal participação acionária the garantia a direção destas outras empresas.

E difícil traçar todas as ligações da Brazil Railway com as empresas do grupo. Sabemos de vínculos de seus diretores - especialmente de Farquhar - com várias empresas que não constam explicitamente dos documentos da Brazil Railway. Ainda assim, com base no port-folio da empresa em 1910 (6), podemos traçar um quadro exemplificativo da rede de ligações da empresa.

Port-folio da Brazil Railway em 1910:

SOROCABANA RAILWAY: 99.800 ações

$£ 175.000$ em obrigações

Arrendamento da exploração da linha

Cia. PAULISTA DE ESTRADAS DE FERRO: 55.000 ações

ESTR. DE FERRO SÃO PAULO-RIO GRANDE: 42.700 ações

Arrendamento da

linha

Cie. AUXILIAIRE DE CHEMIN DE FER AU BRESIL: 24.000 ações

Cie. Ch. de Fer. SUD-OUEST BRESIL: 36.000 ações.

ESTR. DE FERRO MADEIRA-MAMORE: 51.250 ações

BRAZIL LUMBER CO.: Totalidade das açöes

Este esquema, válido para 1910, nos mostra brevemente a estrutura de "holding" da Brazil Railway. Com base num crescente capital-obrigações, a Brazil Railway passava a controlar várias empresas brasileiras ou estrangeiras instaladas no Brasil.

Tomemos o exemplo da Sorocabana Railway. A linha da Sorocabana teve sua construção iniciada em 1872. Sua expansão física é acompanhada da progressiva degradação financeira da empresa responsável por sua operação e construção. No começo deste século, o Governo Federal, principal credor da empresa, acaba por absorvê-la, transferindo-a, em seguida, para o Governo do Estado de São Paulo. Após três anos de operação da linha, o Governo de São Paulo promove seu arrendamento tendo em vista a necessidade de recursos para o programa de valorização do café. Os beneficiários do contrato de arrendamento são Percival Farquhar e Hector Legru que transferem, em seguida, seus direitos à recém formada Sorocabana Railway Company. Embora não haja registro precisos, provavelmente

(6) - MAE. CPC. Vol. 29. p. 46/48. Notice sur la Brazil Railway Co. 
Farquhar e Legru receberam as ações da Sorocabana Railway em pagamento por seus direitos de concessionários. Em seguida devem tê.las vendido, em sua quase totalidade, à Brazil Railway Company, que os pagava com os recursos arrecadados pela emissão de obrigações. Caracterizar-sefa, dessa forma, o chamado lucro do fundador.

Ora, a Sorocabana gera uma renda líquida que constitui a base dos dividendos pagos às ações e dos juros recebidos pelas obrigações. Parte desses dividendos e juros são transferidos à Brazil Railway - enquanto portadora de ações e obrigações da Sorocabana. Esta renda permitia à Brazil Railway satisfazer a seus próprios acionistas e portadores de obrigações. A Brazil Railway se reservava, no entanto, outra fonte de receitas, qual seja, a proveniente da construção de novas linhas e ramais, construção essa quase sempre concedida ao mesmo tempo em que se contratava a exploração de uma linha. Esta era, portanto, outra fonte de recursos para a Brazil Railway fazer frente a seus compromissos diante de acionistas e portadores de obrigações.

Por outro lado, os vínculos entre as diversas empresas do grupo não se davam apenas por meio da própria Brazil Railway. As subsidiárias mantinham também seus "port-folios" com ações e obrigaç̃̃es de outras empresas do grupo de acordo com interesses financeiros imediatos. Alguns observadores julgavam, à época, que esse conjunto de inter-relações podia tornar-se particularmente perigoso num momento de crise em que a falência de uma empresa podia conduzir as demais a situaçăo delicada tal a solidariedade existente entre os vários negócios do grupo.

A expansão da Brazil Railway, a crise que a atinge e sua reorganização são objeto dos próximos tópicos. Não é difícil definir uma cronologia para a história da empresa: de 1906 a 1913, fase de expansão dos negócios por meio da incorporação de grande número de empresa e concessões; de 1914 a 1918, fase de crise e reorganização da empresa, marcada pela intervenção judiciária em sua administração; após 1919, progressiva transformação da empresa em uma "sociedade" cada vez mais distante da gerência de atividades "produtivas".

\section{A EXPANSÃO DOS NEGOCIOS DA BRAZIL RAILWAY.}

E extremamente difícil reconstitutir passo a passo o processo de expansão da Brazil Railway: se, por um lado, podemos identificar as fontes de recursos (emissão de obrigações), por outro é menos claro o processo e o momento pelo qual a Brazil Railway passa a controlar novas empresas. Por vezes, trata-se de compra de ações em Bolsa (como é o caso das estradas de ferro Paulista e Mogiana), fato de registro difícil. Outras vezes as negociações se passam sem registro ou testemunhos muito - claros. 
Os próprios documentos da Brazil Railway disponíveis para o período anterior a 1914 são poucos e nada esclarecedores.

Para suprir tal deficiência, lançamos mão de um quadro geral para o ano de 1913, fornecido por um documento da "Prefecture de Police" de Paris (7). A investigação se dava face aos rumores de quebra iminente da Brazil Railway, rumores esses que reduziram drasticamente as cotações de títulos da companhia na Bolsa de Paris. Assim, as ações privilegiadas, cotadas em 1921 em média a 641 franco, chegaram em 16 de dezembro de 1913 ao nível de 270 francos; do mesmo modo, as ações ordinárias, a 610 francos em 1912, atingiram 200 francos em 16 de dezembro de 1913. Ao mesmo tempo já se anunciava a provável suspensão dos pagamentos de dividendo e de juros no exercício seguinte.

Até entấo, no entanto, a história da Brazil Railway fota de crescimento aceierado em seus negócio. Constituída em 1906, ela tinha por objetivo reunir sob sua direção a rede ferroviária dos estados do Sul do País: São Paulo, Paraná, Santa Catarina e Rio Grande do Sul. Nesse momento existiam aí várias empresas, algumas bem constituídas, em funcionamento $\mathbf{e}$ lucrativas (como a Paulista e a Mogiana, além da chamada Inglesa - a São Paulo Railway Co.), até empresas que começavam a construção de sua linha ou exploravam pequenas parcelas da extensão total concedida (como a São Paulo-Rio Grande). A Brazil Railway adota, aparentemente, uma política não seletiva de incorporação dos negócios ferroviários do sul do país. E para tanto, deve contar com recursos provenientes da emissão de títulos.

O capital autorizado inicial da empresa era de 40 milhões de dólares (equivalentes a 206.800.000 francos). Em 1913, o capital autorizado já ascendera a 60 milhões de dólares, embora a emissão não tivesse atingido esse total, como segue:

\begin{tabular}{|c|c|}
\hline $\begin{array}{l}320.000 \text { açốes ordinárias de } 100 \text { dólares } \ldots \ldots \ldots \\
150.375 \text { ações privilegiadas cumulativas } \ldots \ldots \\
49.625 \text { açôes privilegiadas nâo cumulativas } \ldots \ldots\end{array}$ & $\begin{array}{r}32.000 .000 \text { dólares } \\
15.375 .000 \text { dólares } \\
4.962 .500 \text { dólares }\end{array}$ \\
\hline & \\
\hline
\end{tabular}

(7) - MAE. CPC. Vol. 32. Prefecture de Police. Cabinet du Préfet. Note sur la Brazil Railway Co. février 1914.

(8) - A Noroeste, empresa brasileira, teve o objetivo de construir e operar uma linha que, partindo de São Paulo (Bauru), atingisse a fronteira do Brasil no Estado do Mato-Grosso . Nesta empresa, além de diretores franceses encontramos Teixeira Soares e atribui-se a Hector Legru alguma influência na fase de sua formação. 
Não foi possível acompanhar minuciosamente o processo de emissão e de distribuição de ações da Brazil Railway, mas em sua maior parte parece se pautar pela regra enunciada anteriormente: trata-se de emissão sem a correspondente realização em dinheiro do valor das ações, com sua posterior atribuição aos "fundadores", que podiam conservá-las cu vendêlas no mercado obtendo, de imediato, lucros elevados. Embora possa haver algumas nuances nesta regra geral (dependendo do tipo de ações envolvidas ou da distribuição das ações num momento dado), parece-nos que este capital-ações de grande vulto não se traduziu num aporte de recursos monetários substancial para os negócios da empresa.

Desse modo, para financiar sua expansão, a Brazil Railway tinha de lançar mão da emissão de obrigações, recursos esses que passam a ser chamados pela empresa de "capital-obrigações". Rigorosamente, no entanto, não se trata de um capital e sim de uma divida de longo prazo que tem o direito de auferir uma renda fixa e que é objeto de amortização parcial ano a ano.

As obrigações da Brazil Railway foram lançadas principalmente na Inglaterra, na França e na Bélgica, atingindo vulto considerável diante do capital da empresa. Senão vejamos:

$$
\begin{aligned}
& \text { I . } £ 10.018 .876 \text { em obrigações }(4,5 \% \text { ao ano })=250.472 .000 \text { FF } \\
& \text { II . US\$ } 1.510 .500 \text { em obrigações }(5 \% \text { ao ano })=7.552 .500 \mathrm{FF} \\
& \text { III . Série francesa-obrigaçốes }(4,5 \% \text { ao ano) }=86.500 .000 \mathrm{FF} \\
& \text { IV . } 22.000 .000 \text { em obrigações }(5 \% \text { ao ano) }=50.000 .000 \mathrm{FF} \\
& \mathrm{V} \text {. Bônus }(6 \% \text { ao ano) }=100.000 .000 \mathrm{FF}
\end{aligned}
$$

Como vemos, para um capital ações de aproximadamente 250.000.000 FF havia obrigações de cerca de $500.000 .000 \mathrm{FF}$. Trata-se, em ambos os casos, de recursos diretamente absorvidos em nome da Brazil Railway Company. Mas, como dissemos, ela era uma "holding" de outras empresas que, muitas vezes, também lançaram suas ações e obrigações nos mercados europeus. Vale pois registrar o conjunto de interesses que a "Prefecture de Police" de Paris (no mesmo documento anteriormente citado) reconhecia como vinculados à Brazil Railway, interesses esses adquiridos entre 1906 e 1913:

I. Exploração direta de estradas de ferro:

1. Sorocabana Railway

2. Estrada de Ferro São Paulo-Rio Grande

3. Linhas férreas do Paraná

4. Cie. Auxiliare des Chemins de fer au Brésil

II. Participação em diversas linhas ferroviárias:

5. Cia. Paulista de Estradas de Ferro

6. Cia Mogiana de Estradas de Ferro 


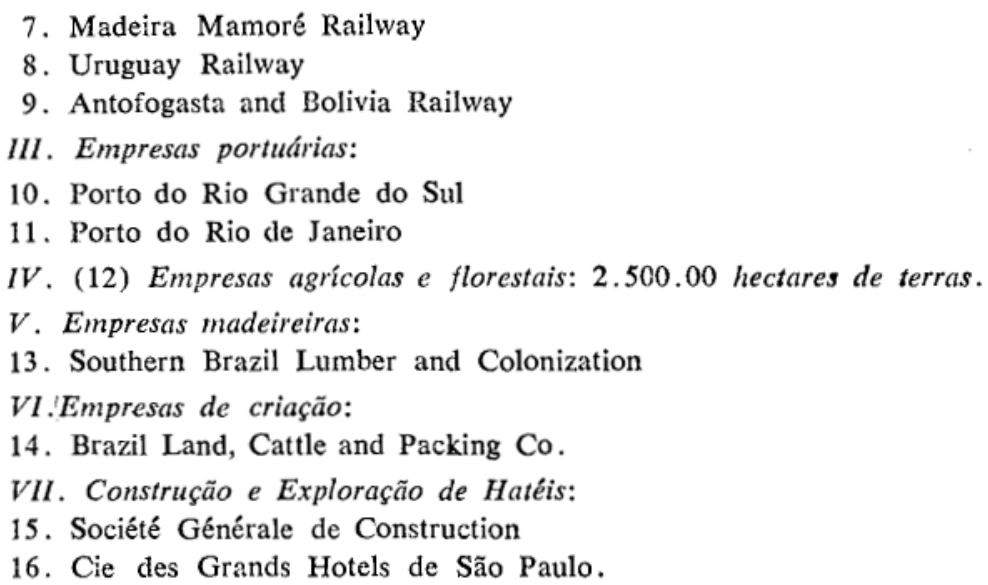

Estas eram as empresas cujos vínculos com a Brasil Railway se estabeleciam de modo claro, ou seja, a própria documentação da empresa reconhecia a propriedade de ações dessas outras sociedades. Como se vê, ela abarca grande parte (quase a totalidade) das estradas de ferro do Sul do país, dois portos de grande importância e outras empresas.

Mas o grupo da Brazil Railway tinha interesses mais vastos. Os principais elementos do grupo - Faqhar e Legru - estavam presentes em outros negócios. Farquhar fora, de início, diretor da Rio de Janeiro Light and Power Co., mas parece dela se ter desligado após a formação da Brazil Railway. Legru, banqueiro parisiense, parece associar-se a Farquhar com a finalidade de facilitar a penetração nos mercados europeus de capitais. Várias instituições financeiras francesas dão apoio constante ao lançamento de ações e obrigações das empresas do grupo no mercado de $\mathrm{Pa}$ ris. Entre elas, basta citar Société Générale e Banque de Paris et des Pays Bas para avaliar o vulto dessas transações.

Se procurarmos os nomes de Farquhar e Legru e de outros dirigentes da Brazil Railway (como Quellenec, Pearson, Mackenzie, Hubbard, Teixeira Soares, Carlos Sampaio), poderemos encontrá-los em várias empresas não identificadas de imediato com a Brazil Railway Co..

Este é sem dúvida o caso da Companhia do Porto do Pará, cujos vínculos não se limitam ao controle por elementos do mesmo grupo. Embora se trate de empresas separadas da Brazil Railway, o Porto do Pará tinha importante participação acionária (cerca de 50\%) na Madeira-Mamoré, empresa que, como vimos, estava relacionada no "port-fólio" da Brazil Railway.

Outras ligações parecem ter existido, tais como a Companhia de Estradas de Ferro Noroeste do Brasil, a Companhia de Estrada de Ferro Vi- 
tória-Minas. Trata-se, entretanto, de outro aspecto da expansão da em. presa que não poderemos explorar neste texto.

Definida a amplitude dos negócios da Brazil Railway Co. em seu momento de máxima expansão, cabe tentar discutir as origens da crise que sobre ela se abate e seus efeitos imediatos.

\section{A Crise da Brazil Railway: reflexo dos efeitos da Primeira Guerro Mundial ou decorrência de sua própria estrutura?}

Como notamos, já em fins de 1913 havia sérias suspeitas de ưma quebra iminente da Brazil Railway. O documento citado anteriormente (produzido pela Prefecture de Police de Paris) tinha em vista exatamente avaliar se os rumores a esse respeito eram fundados.

Efetivamente, no correr de 1914, a companhia suspende o pagamento de juros de obrigações e de dividendos das ações (parcial ou integralmente), iniciando um processo demorado de transformação de sua estrutura.

Os anos de 1914 a 1918 marcam, do ponto de vista jurídico, uma situação transitória: em outubro de 1914, diante do não pagamento de juros de obrłgações, a Corte Federal de Justiça do Estado do Maine (EUA) nomeou um "receiver" (que interpretamos como sendo um interventor ou administrador judiciário). Este regime durará até o fim do ano de 1918.

Em primeiro lugar, cabe indagar das razões que conduzem à insolvência da Brazil Railway Company.

Sem dúvida, não podemos ignorar os efeitos da Primeira Guerra Mundial para a economia brasileira que atingem também as finanças do Governo Federal e, em consequência, a Brazil Railway. Reduzidas as exportações brasileiras e, portanto, a entrada de divisas, define-se situação e crise no mercado cambial acentuada pela tendência ao retorno de capitais para seus países de origem. O Governo Federal brasileiro, também ele devedor nos mercados de capitais da Europa, suspende o pagamento do serviço da dívida o que conduz a um acordo - o chamado Furding de 1914 - com os credores liderados pela casa Rothschild de Londres.

A Brazil Railway também sofria os efeitos da Guerra por intermédio de suas filiais, subsidiários e coligadas. Observava-se à época que a renda da empresa derivava das seguintes fontes:

\footnotetext{
"19 juros e dividendos produzidos pelos títulos das sociedades filiais: $2^{\circ}$ do produto de suas redes e empresas quando ela própria assegura a exploração; $3^{\circ}$ do lucro realizado nas obras que ela afetua por sua conta" (9).
}

Evidentemente, os dois primeiros ítens, derivados da exploração das empresas ferroviárias e portuarias, devia sofrer o impacto do reduzido 
movimento comercial nos anos de guerra. Além disso, algumas empresas que tinham a "garantia de juros" do Governo sofrem atrasos ou recebem, em pagamento, apenas títulos da dívida interna ou externa. Quanto ao último ítem - lucro na construção de obras - tal renda dependia de contratos com o Governo, sujeitos portanto aos atrasos referidos acima.

Tais fatos conjunturais eram ressaltados pelos administradores da Brazil Railway, atribuindo a crise da empresa em especial ao não pagamento pelo Governo Federal de parcelas importantes. A relevância desta dívida era ressaltada numa carta do representante do Governo francês no Brasil:

"Dans mes rapports au sujet des negociations du grand emprunt brésilien,
j'ai exposé au predecesseur de Votre Excellence l'objet des efforts des
representants de la Banque de Paris et des Pays Bas et de la Société
Générale qui était d'obtenir qu'une part de cet emprunt fut affectée au
paiement de toutes les sommes dues par le Gouvernement à la Brazil
Railway Company, principalement pour le chemin de fer Madeira-Ma-
moré que cette compagnie construisait pour le compte de l'État" (10).

Admitia-se, então, que esta era a única possibilidade de evitar a insolvência da empresa. Os dois grandes bancos franceses tentam atuar em favor da Brazil Railway, embora sem sucesso.

Não parece razoável admitir, no entanto, que a crise da Brazil Railway decorresse apenas da situação excepcional da Primeira Guerra Mundial mesmo que ela a tivesse precipitado. Já indicamos que importante parte do lucro da empresa provinha de obras que realizava por conta do Governo. Embora houvesse ainda em 1913, de acordo com contratos firmados, cerca de $3.000 \mathrm{~km}$ de linhas a construir, havia também a necessidade de levantar capitais no exterior para cada novo trecho a ser construído. Embora o Governo cferecesse garantia de juros sobre os capitais levantados (em limites previamente estabelecidos), a empresa devia enfrentar, no mercado de capitais, condições menos flexíveis e crescentes taxas de juros, isto já no limiar da Primeira Grande Guerra.

Por outro lado, a estrutura do capital da empresa e de suas subsidiárias e o verdadeiro emaranhado constituído pela rede de relações entre elas conduzia a tal solidariedade de interesses que o fracasso de uma delas acabaria precipitando a queda das demais, considerada uma conjuntura econômica particularmentte desfavorável.

(9) - MAE. CPC. Vol. 33. p. 23/26. Office National des Valeurs Mobiliers. 8-9-1915.

(10) - MAE. CPC. Vol. 32. p. 197 e ss. Légation de la République Fran. çaise au Brésil. 5-1T 1914. 
Numa perspectiva de longo prazo, no entanto, acreditamos que a Primeira Guerra apenas antecipou um desmantelamento que seria inevitável dada a forma de organização da empresa.

Por um lado, com a amortização progressiva das obrigações, a parcela restante do "capital-obrigações" devia continuar a sustentar o mesmo capital-ações cuja carga relativa era proporcionalmente maior. Apenas por meio de elevada rentabilidade e alto grau de capitalização interna seria possível substituir o capital-obrigações amortizado ano a ano por recursos novos gerados pela operação da empresa.

Para tanto, seria necessário contar com rentabilidade elevadíssima nas diversas empresas. No entanto, não era esse o caso das empresas do grupo do Brasil Railway em sua grande maioria. Em 1915, o "receiver" da empresa fazia a scguinte apreciação dos principais negscios do grupo (11); entre as empresas ferroviárias, Paulista e Mogiana eram as únicas a não oferecer problemas imediatos pois ainda distribuiam dividendes e deviam continuar a facêt-lc se a crise não se agravasse; na Sorocabana, a renda líquida era insuficiente para cobrir o serviço da dívida da empresa: a São Paulo-Rio Grande era deficitária no plano operacional e o Governo Federal vinha pagando a garantia de juros cm bônus ¿ outros titulos da divida pública; quanto às linhas do Paraná, acréditava o "receiver" que, sem a reforma do contrato, melhor seria abandonar a empresa pois sua construção e operaçãao eram muito onerosas; a Cie. Auxiliaire não cunseguia, $\mathrm{ccm}$ sua renda cperacional, cumprir as cláusulas so contrato de arrendamento; as linkas do Lruguai ofereciam dividendos e finalmente para a MadeiraMamoré, ćinda $\mathrm{cm}$ construção, o custo efetivu das obras vinha sendo superior à garantia oferecida pelo Governo o qual. de resto, havia suspenso os pagamentis Percebe-se, portanto, que do amplo complexo ferroviaric da Brazil Railway, apenas três linhas não ofereciam maiores problemas em wrno de 1915.

As chamadas empresas "industriais" apareciam mais como esperança do que como fcnte de renda imediata. Pelo contrário, de imediato essas empresas (madeira, gado, frigorífico) apenas exigiam novos recursos pois ainda não estavam operando de forma plena.

Quanto aos portos, não havia comentários mais precisos, mas o elevado nível de endividamento das empresas devia ser particularmente oneroso diante do possível saldo operacional de tais empresas.

Mais problemático, nesse momento, era o fato de que, para poder manter em funcionamento o "sistema" da Brazil Railway, havia necessidade de novos recursos, tarefas difícil diante da situação da empresa e do

(11) - MAE. CPC. Vol. 33. p. 23/6. 
mercado de capitais. Como encaminhar, portanto, a "solução" para a Brazil Railway Company?

No mesmo documento acima citado, o "receiver" já apontava o caminho a seguir para a reorganização da empresa: em essência, os portadores de obrigações (detentores de títulos da renda fixa) deveriam se conformar, a partir daí, com uma "renda variável" até que a situação da empresa comportasse o retorno aos níveis originais de juros previstos na emissão dos títulos. Ao mesmo tempo, o pagamento eventual de dividendos aos acionistas ficava condicionado ao integral pagamento dos juros das obriga. çॅ̄es.

Essa a principal transformação que se estabelece no "Acordo com os portadores de obrigações" de 18 de julho de 1917 (12). De modo geral, as obrigaçōes da Brazil Railway foram transformadas em títulos de renda variável (de início não cumulativas), cujo rendimento efetivo seria fruto d $\varepsilon$ distribuição proporcional do resultado líquido do grupo entre as diferentes séries de obrigações.

Ao mesmo tempo, a reorganização implicava na transferência do controle da empresa para os comitês de portadores de obrigações que designariam um Comitê Conjunto de portadores e este, afinal, o Conselho de administração e o Conselho diretor.

Para a obtenção de novos recursos foi autorizada também a emissão de novos títulos (Prior Lien Bonds - 6\%) no valor total de 80.000 .000 de francos, mas que não chegaram a ser colocados no mercado.

No comitê conjunto de portadores de obrigações, prevaleciam, em número de votos, as proporções de títulos colocadas em cada mercado europeu. A importância dos interesses franceses no grupo pode ser avaliada pela distribuição transcrita abaixo:

Obrigaçōes internacionais:

Série francesa:

Debêntures conversíveis:

Notas $6 \%$ :

A emitir (previsão) Debêntures (Prior Lien Bonds):

$\begin{array}{lr}\text { membro belga: } & £ 3.656 .000-37 \text { votos } \\ \text { membro inglês: } & £ 4.386 .000-44 \text { votos } \\ \text { membro francês: } & £ 2.507 .000-25 \text { votos } \\ \text { membro francês: } & £ 3.408 .000-34 \text { votos } \\ \text { membro inglês: } & £ 2.000 .000-20 \text { votos } \\ \text { membro francês: } & £ 5.804 .000-58 \text { votos } \\ \text { membro belga: } & 10 \text { votos } \\ \text { membro francês: } & 12 \text { votos } \\ \text { membro inglês: } & 12 \text { votos }\end{array}$

(12) - MF. B 32.798. Note. Arrengement entre la Compagnie, les Obliga taires, les Créanciers garantis et les Actionnaires. 18-7-1917. 
Definia-se, dessa forma, o primeiro passo na reorganização da Brazil Railway, qual seja sua mudança de direção e também a nova composição e remuneração do capital. De certo modo, credores foram transformados em acionistas, uma vez que os portadores de obrigações passaram a ter o direito de indicar a direção da empresa ao mesmo tempo em que perdiam sua "renda fixa" para auferir, quando possível, uma renda proporcional aos resultados da empresa. Company.

Vejamos, então, a que conduz esta nova orientação da Brazil Railway V. Brazil Railway: sua transformação de "holding" de concessionárias de serviços de utilidade pública para uma empresa de port-folio.

O acordo estabelecido entre a Brazil Railway e os representantes dos portadores de obrigações é a base para o encerramento da "receivership", o que efetivamente ocorre em 31 de dezembro de 1918. Com isso, o negócio recebe uma nova direção, os fundadores - ou seja, o grupo de Farquhar e Legru - são deslocados da direção uma vez que os acionistas, ao lado da negociação com os credores, abriram mão do direito de indicar os conselhos dirigentes.

Formalmente, a administração da empresa fora transferida aos portadores de obrigações, representados por seus comitês de defesa. Estes indicariam os representantes do Comitê Conjunto dos Portadores de Obrigações que, por sua vez, nomearia o Conselho de Administração e os diretores da empresa. Uma afirmativa segura sobre os interesses representados nestes comitês é difícil de ser adiantada. Parece certo, no entanto, que os grandes bancos, pelo menos no caso francês, acabaram sendo investidos nos cargos dos comitês de representantes de portadores de obrigações. E claro, estes, em grande número, necessitavam de organismos que os reagrupassem. Isto ocorre, quase sempre, por meio do "Office National de Valeurs Mobiliers" (depois Association Nationale des Porteurs Français de Valeurs Mobiliers), cujos vínculos com os grandes grupos financeiros são mais do que prováveis. Basta lembrar que o secretário geral do Office National em 1971 - Jules Chevalier - que vem ao Brasil para negociar com o Governo Federal o acerto do atraso de diversos títulos brasileiros colocados no mercado francês, logo depois é nomeado diretor do Banque de Paris et des Pays Bas.

Desse modo, se um julgamento nos é permitido, acreditamos que após 1919, a Brazil Railway passa efetivamente a ser controlada pelos grandes bancos internacionais que tinham vínculos com a empresa na qualidade de lançadores de títulos no mercado europeu. Vale dizer, esses bancos também eram acionistas da empresa quando de sua crise em 1914. 
Mais importante, no entanto, é que ela passa a ser gerida como uma financeira: se antes prevalecera uma política de negócios arrojada e otimista, agora procura-se obter um resultado seguro a partir de situações perfeitamente definidas. Com previsões menos otimistas, a nova administração progressivamente liquida ou tranfere negócios cujos resultados imediatos não eram compensadores. Com isso, deixa de existir o vínculo da empresa com a atividade "produtiva" (transportes, portos etc), mas continua a existir uma sociedade com um ativo e passivo financeiros (ou seja, representados por títulos) a serem geridos pela administração da Brazil Railway Company.

As primeiras decisões da nova direção da Brazil Railway foram exatamente no sentido de abandonar certos negócios e redâzir a necessidade de novos recursos. Assim, já em 1919 e 1920, três contratos de arrendamento ou gerência são rescindidos: o porto do Rio Grande do Sul é transferido ao Governo daquele Estado por 200.000.000 de francos (140 em espécie e 60 em aṕlices do Estado); ainda em 1919, o antigo grupo concessionário da Cie. Auxiliare recompra o ativo da empresa por 220.000.000 de francos: em 1920, o Governo do Estado de São Paulo assina a rescisão do arrecadamento da Sorocabana, pagando 48.700 contos de réis (ou 3.000.000 de libras) pela concessão da rede (13).

Admitia-se, desse modo, que o volume de recursos necessários para a Companhia havia se reduzido de 80.000 .000 de francos( ou mais, dada a desvalorização da moeda francesa no período) para cerca de 10.000 .000 de francos. (14)

Além disso, em 1922 a Companhia do Porto do Rio de Janeiro, do grupo Brazil Railway, não se apresenta para a concorrência em que poderia renovar o contrato de exploração do porto, sabedora de que outros grupos estavam dispostos a comprar suas ações (15).

A breve observação do balanço da Brazil Railway e subsidiárias em 1932 nos mostra o resultado deste progressivo processo de transformação da empresa. Como holding, ela continuava a possuir títulos em seu port-fólio. Vejamos, no entanto, a natureza destes títulos:

1. Renda interna paraguaia

2. Sorocabana Railway-debêntures e ações. A Sorocabana é também, neste momento, uma empresa de port-fólio (contituído prin-

(13) - ibidem.

(14) - Brazil Railway Co. Rapport du Conseil d'Administration aux actionnaire pour l'exercice 1919. Archives Nationales. 65 AQ-E 111.

(15) - MAE. Amérique. Brésil. Vol. 48. Telegramme: MAE à Consul français à $S$. Paulo.

MAE. Amérique. Brésil. Vol. 84. Ambassade de la République française au Brésil. 25-10-192.. 
cipalmente por Apólices do Governo do Estado de São Paulo). Não há mais a gestão da estrada de ferro.

3. Cia. Estrada de Ferro São Paulo-Rio Grande: ações. Teve a ges tão da empresa até 1930 quando o Governo Federal a ocupou e passou a administrá-la.

4. Cie Auxiliaire: ações. Também é uma empresa de port-fólio, ou seja, seu ativo é constituído apenas por títulos diversos.

5. Cia Paulista de Estradas de Ferro e Cia. Mogiana de Estradas de Ferro: ações. Tem participação no capital que se reduz progressivamente venda de ações ou não subscrição de aumento de capital), não controlando mais a administração dessas duas empresas ferroviárias.

6. Cia Estrada de Ferro Norte do Paraná: totalidade das ações. Também ocupada pelo Governo Federal em 1930.

7. Southern São Paulo Raikway Co: ações e debêntures. O ativo desta empresa é constituxdo por obrigações da dívida interna do Estado de São Paulo (pois a empresa também foi transferida ao Governo desse Estado).

8. Cia Docas do Rio de Janeiro e Cia do Porto do Rio de Janeiro: não tem mais a gerência do porto mas possuem imóveis naquela cidade e valores diversos em seu port-fólio.

9. Porto do Pará: obrigações. Esta companhia está em demanda com o Governo Federal para receber a garantia de juros.

10. Cia Francesa do Porto do Rio Grande do Sul: ações. Também não gere mais o referido porto. Tem títulos em seu port-fólio e, em especial, obrigações do Governo do Rio Grande do Sul.

11. Southern Brazil Lumber and Colonisation Co.: ações, créditos. Em operação, alterna saldos e deficits.

12. Barcelone Traction, Light and Power Co.: ações, sem controle da administração.

13. Royaume de Bélgique: títulos de empréstimo.

14. Cia Indústria Brasileira de Papel: ações e créditos. Em operação.

15. Empresa Armazéns Frigoríficos: ações. Em operação, com lucros.

16. Brazil Land, Cattle and Docking Co.: em operação. Obrigaçōes (16).

(16) - MF. B 32.798. Brazil Railway Co. Rapport du Comité Conjoint d’Obligataires. 1932. Paris, Imprimerie Chaix, 1933. 
Como se observa, a Brazil Railway, em fins dos anos vinte, so mantivera duas empresas ferroviárias sob seu controle (São Paulo-Rio Grande, Norte do Paraná), tendo rescindido o contrato de arrendamento ou transferido o controle acionário das demais (Paulista, Mogiana, Sorocabana, Southern São Paulo, Auxiliares); não mais geria diretamente nenhum porto embora mantivesse títulos do Porto do Pará; continuava a operar empresas de porte relativamente reduzido (madeira, gado, papel, frigoríficos) em claro contraste com o vulto de seus negócios no período de 1906 a 1913.

Resta uma questão a ser colocada: por que, apesar dessa profunda transformação, a Brazil Railway subsiste?

Sem pretendermos uma resposta definitiva, uma questão nos vem à mente de imediato. O franco francês sofre profunda desvalorização entre 1914 e 1926. Grande parte dos encargos da Brazil Railway eram pagáveis em francos. Consequentemente, os encargos, em termos reais, sofreram redução proporcional à desvalorização em moeda francesa. Provavelmente, este mecanismo deve ter propiciado condições de sobrevivência à empresa, com perdas progressivas para seus credores e, possivelmente, ganhos para a direção da empresa. Não se trata evidentemente de uma conclusão absoluta, mas um tema cuja pesquisa subsequente poderá esclarecer.

\section{CONCLUSÃO.}

Algumas conclusões gerais podem ser sugeridas pela história da Brazil Railway Company. Como observamos anteriormente, trata-se apenas de um conjunto de hipóteses em torno das quais pretendemos orientar nossa pesquisa futura. Tais hipóteses, em certo sentido, vão além da evidência apontada no texto e fazem uso de informações coletadas e não presentes na exposição.

1. Os investimentos franceses no Brasil, embora conduzidas por grandes instituições financeiras, não levaram ao controle efetivo dos empreendimentos. Além de uma grande parcela de recursos destinados a empréstimos públicos, muitos investimentos em ações e obrigaçōes de empresas estabelecidas no Brasil se fizeram sem que houvesse a preocupação de efetivo controle da gestão da empresa em função dos interesses franceses. O Governo francês tenta (por meio do Ministério das Finanças e do Ministério das Relações Exteriores) canalizar a possível influência desses investimentos para a França: sempre que se solicita a admissão de um novo título à Bolsa de Paris, exige-se em contrapartida a inclusão de administradores franceses e o compromisso de encomendas para a indústria francesa. Os resultados práticos dessas medidas, no entanto, não parecem ter sido apreciáveis. 
2. Definido o caráter predominante financeiro dos investimentos fran. ceses, não é difícil perceber que seu rendimento também esteve sujeito às constantes flutuações financeiras por que passou a economia brasileira e, em particular, o Governo Federal. Aparentemente, o investidor francês apreciava mais a existência de uma garantia de juros do Governo brasileiro do que uma base sólida para a empresa em que se investia. Como em 1914 e 1930, o Governo brasileiro se vê obrigado a suspender diversos pagamentos de dívidas externa, os investidores franceses foram particularmente afetados em suas relações com o Brasil.

3. Como notamos, houve a partir da Primeira Guerra Mundial, acentuada desvalorização do franco francês face à libra esterlina( e outras moedas). Os devedores brasileiros aproveitaram esta situação para reduzirem substancialmente o saldo de seus empréstimos, com evidente prejuízo para os investidores franceses que recebiam o mesmo valor nominal previsto em seus títulos. Apenas em 1929, um julgamento da Corte de Haia obriga o Governo Federal a pagar alguns de seus empréstimos em francos-ouro. Mas este julgamento abarcou apenas uma parcela da dí vida do Governo Federal. Além disso, com a crise dos anos trinta e a nova suspensão dos pagamentos, tal julgamento não tem nenhum efeito prático imediato.

4. Em suma, os insucessos dos investimientos franceses no Brasil parecem se associar a seu caráter eminentemente financeiro, sem que houvesse exame cuidadoso das atividades, que iriam sustentar os títulos emitidos. Mesmo no caso da Brazil Railway, vários investimentos deveriam parecer fadados ao fracasso como empresas, mesmo que pudessem contar com a garantia de juros do Governo por um período mais ou menos longo. Trata-se, portanto, quase sempre da busca de lucros imediatos sem análise mais detida da natureza dos investimentos realizados.

Em relação ao Brasil, o que pensar dos investimentos franceses?

5. Em primeiro lugar, eles se dirigiram para os setores "clássicos" da economia brasileira, isto é, setores ligados essencialmente à agro-exportação . Nesse sentido, vieram reiterar o caráter da economia brasileira não sendo, nesse sentido, um elemento de transformação de suas características. Isto não quer dizer que a maciça entrada de recursos externos não tenha ne. nhum impacto sobre a economia (por exemplo no sentido da industrializa. ção), mas simplesmente de que não se trata de uma efeito claro e direto nesse rumo.

6. Por outro lado, os investimentos franceses impuseram ao Brasil uma restrição de ordem financeira. Embora frequentemente o país tivesse suspenso o pagamento da dívida externa, a economia brasileira se via, a cada novo compromisso externo, financeiramente "internacionali- 
zada": ou seja, o funcionamento da economia passava a exigir proporções crescentes de divisas. E inegável que este fato responde pelas crises de insolvência externa do Governo brasileiro, parecendo-nos mesmo mais importante este aspecto do que o do controle de certos setores "produtivos"

Estas as hipóteses apresentadas a título de conclusão, hipóteses essas sugeridas pela experiência dos investimentos franceses na Brazil Railway Company. 